\title{
Antimicrobial Resistance and Sensitivity among Isolates of Esherichia coli from Urine Samples in Denizli, Turkey
}

\author{
Selma Kirac ${ }^{*}$, Dilek Keskin ${ }^{2}$, F. Banu Karahasanoğlu ${ }^{3}$ \\ ${ }^{1}$ Denizli Health Services Vocational High School, Pamukkale University, Denizli, TURKEY \\ ${ }^{2}$ Cine Vocational High School, Adnan Menderes University, 09500- Cine-Aydin, TURKEY \\ ${ }^{3}$ ER-PA Special Health Hospital, Denizli, TURKEY \\ *Email for Correspondence: skirac@pau.edu.tr
}

\begin{abstract}
Objective: The research was carried out with isolate and determines the antimicrobial sensitivity in E. coli from urinary tract infections in special hospital in Denizli and recorded at specimens.

Methods: Urine samples $(n=21)$ were collected from patients with signs and symptoms of Urinary tract infections. Bacteria were isolated and identified by conventional biochemical profile. Antibiotic resistance pattern of E. coli against different antibiotic was determined by Kirby-Baur method.

Results: The results revealed that sensitivity rate of antimicrobial agents were in the range of meropenem $(100 \%)$, norfloxacin and ciprofloxacin $(86 \%)$, cefotaxime $(80 \%)$, aztreonam $(76 \%)$. None of the samples showed no resistance to amikacin, ceftazidime, aztreonam, amoxicillin/clavulanic acid, and meropenem. Out of 21 isolates, 3(14\%) isolates showed Multiple Antibiotic Resistance ten to thirteen antibiotics.

Conclusion: It is concluded that most of the urinary tract infections in human are caused by E.coli exhibited highest resistance to meropenem $(100 \%)$, followed by norfloxacin and ciprofloxacin $(86 \%)$.
\end{abstract}

Key words: Escherichia coli, Antibiotic, Resistance, Prevalence, MDR

This article is is licensed under a Creative Commons Attribution-NonCommercial 4.0 International License.

Attribution-NonCommercial (CC BY-NC) license lets others remix, tweak, and build upon work non-commercially, and although the new works must also acknowledge \& be non-commercial.

\section{INTRODUCTION}

Antibiotic resistance is recognized worldwide as a major problem in the management of patients hospitalized with serious infections (Swartz, 1994). Turkish hospitals also face increasing numbers of antibiotic-resistant organisms including Klebsiella pneumonia, Pseudomonas aeruginosa, Methicillin resistance in Staphylococcus aureus, Escherichia coli (Toroglu and Keskin, 2011, Toroglu et al., 2013, Yakupoguları et al., 2006).

E. coli are gram negative, facultative bacteria that ferment glucose and are members of the family Enterobacteriaceae (Feng and Weagant, 2009 ). They are mainly allocated in the intestine of animals and forms part of the normal intestinal flora that maintains the physiology of a healthy animal (Conway and Macfarlane, 1995). Thus, most E.coli strains are nonpathogenic but pathogenic strains that cause gastrointestinal illness in humans and opportunistic ones that normally affect immune compromised patients exists (Nataro and Kaper, 1998). For example, more than $80 \%$ of urinary tract infections occur in outpatients and E.coli accounts for more than $50 \%$ of the infections in these patients (Blomgran et al.,2004, Jha and Bapat, 2005). In rare cases, virulent strains are also responsible for Haemolytic Uremic Syndrome (HUS), peritonitis, mastitis septicemia, and gram-negative pneumonia Olowe et al., 2003). It is one of the organisms most frequently isolated from different clinical cases of diarrhea and others (Okeke et al.,1999, Tobih et al., 2006).

We aimed in these research to determine the status of antibiotic resistance, underlying conditions, and isolation of E.coli isolates with from a special hospital in Denizli, Turkey. 


\section{SubJeCtS AND Methods}

Isolation of bacterial strains and identification: 21 isolates were determined from special hospital patients in Denizli July and August in 2013 and recorded at specimens. Mac Conkey agar and EMB agar (Eosin Methylene Blue) agar used for E.coli isolation. Isolates were considered to be presumptive Escherichia spp. Gram-Negative bacilli, mucoid colonies and lactose positive. Confirmation of isolates was performed by using classic chemical tests (motility test, ure hydrolysis, acid production from mannitol, production of $\mathrm{H}_{2} \mathrm{~S}$, IMVIC (Indol, Metil Red, Voges-Proskauer and Citrate) (Prakash et al., 2011, Cowan and Steel, 1970).

\section{Antibiotic resistance activity}

Antibiotic resistance was determined by an agar disc diffusion test (Bauer et al., 1996) using Mueller-Hinton agar (Difco) according to Clinical and Laboratory Standards Institute (CLSI., 2005) recommendations. Twenty different antibiotics were used. For antibiotic resistance determination, the isolates were grown in Luria- Bertani (LB) broth until the turbidity equal to the $0.5 \mathrm{Mc}$ Farland standart. Cultures were swabbed on to the Mueller-Hinton agar and all isolates were tested against

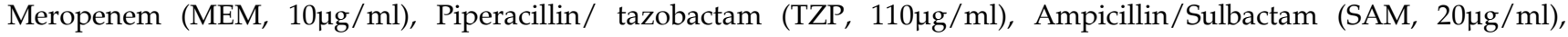
Amikacin $(\mathrm{AK}, 30 \mu \mathrm{g} / \mathrm{ml})$, Ceftazidime $(\mathrm{CAZ}, 30 \mu \mathrm{g} / \mathrm{ml})$, Tobramycin $(\mathrm{TOB}, 10 \mu \mathrm{g} / \mathrm{ml})$, Amoxycillin /clavulanic acid (AMC,

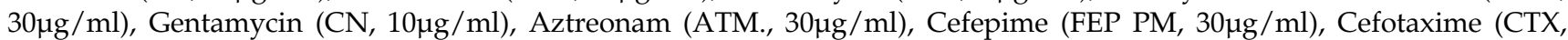

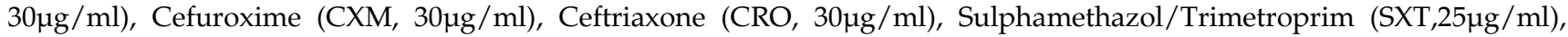

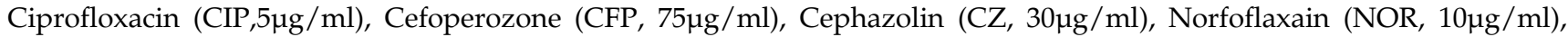
Ampicillin (AM, 10 $\mu \mathrm{g} / \mathrm{ml})$, Cefixime (CFM, $5 \mu \mathrm{g} / \mathrm{ml})$.

The isolates those grown in inoculation were evaluated as resistant, and the others were evaluated as susceptible (Bauer et al., 1996). The antibiotic discs were dispensed sufficiently separated from each other so as to avoid overlapping of inhibition zones. The plates were incubated at $37^{\circ} \mathrm{C}$, and the diameters of the inhibition zones were measured after $18 \mathrm{~h}$. All susceptibility tests were carried out in duplicate and were repeated twice if discordant results had been obtained.

\section{Multiple Antibiotic Resistance Index:}

For all isolates, we calculated the MAR index values (a/b, where a represents the number of antibiotics the isolate was resistant to, $\mathrm{b}$ represents the total number of antibiotics the isolate tested against). A MAR index value $\geq 0.2$ is observed when isolates are exposed to high-risk sources of human or animal contamination, where antibiotics use is common; in contrast a MAR index value $<$ or $=0.2$ observed when antibiotics are seldom or never used (Krumperman, 1985, Matyar et al., 2008).

Results The sensitivity of E.coli isolates to antimicrobial agents $(\mathrm{n}=21)$ gave high sensitive rates found that E.coli isolates diffusion tests for meropenem (100\%), norfloxacin and ciprofloxacin (86\%), cefotaxime (80\%), aztreonam (76\%). None of the samples showed no resistance to amikacin, ceftazidime, aztreonam, amoxicillin/clavulanic acid, and meropenem. The results were given table 1 .

\section{Discussion}

Carbapenems, mainly meropenem, sensitivity rate of meropenem was showed in $100 \%$. Some researchers have reported meropenem sensitivity rate to E.coli from 100\% to 90.9\% (İnan and Gurler, 2004, Y1lmaz et al., 2010, Barisic et al., 2003). Our results were similar to Yilmaz et al.,(2010) who also reported that percentage of meropenem sensitivity was $100 \%$ in Turkey. It can be suggested that meropenem can be used for infections based on E.coli.

Table 1: Antibiotic resistance pattern of Escherichia coli isolated from urine samples

\begin{tabular}{|l|c|c|c|}
\hline Antibiotics & Sensitive & Intermediate & Resistance \\
\hline MEM & $21(\% 100)$ & $(\% 0)$ & $(\% 0)$ \\
NOR & $18(\% 86)$ & $(\% 0)$ & $3(\% 14)$ \\
CIP & $18(\% 86)$ & $(\% 0)$ & $3(\% 14)$ \\
CTX & $17(\% 80)$ & $3(\% 14)$ & $1(\% 5)$ \\
ATM & $16(\% 76)$ & $5(\% 24)$ & $(\% 0)$ \\
CAZ & $15(\% 71)$ & $5(\% 24)$ & $(\% 0)$ \\
FEP PM & $15(\% 71)$ & $5(\% 24)$ & $1(\% 5)$ \\
CFM & $13(\% 62)$ & $5(\% 24)$ & $3(\% 14)$ \\
CRO & $12(\% 57)$ & $6(\% 29)$ & $3(\% 14)$ \\
TZP & $12(\% 57)$ & $9(\% 42)$ & $(\% 0)$ \\
SXT & $11(\% 57)$ & $4(\% 19)$ & $6(\% 29)$ \\
CFP & $10(\% 48)$ & $8(\% 4)$ & $3(\% 14)$ \\
CXM & $9(\% 42)$ & $8(\% 38)$ & $4(\% 19)$ \\
AMC & $8(\% 38)$ & $13(\% 62)$ & $(\% 0)$ \\
AK & $7(\% 33)$ & $14(\% 67)$ & $(\% 0)$ \\
CN & $6(\% 29)$ & $12(\% 57)$ & $5(\% 21)$ \\
TOB & $4(\% 19)$ & $16(\% 76)$ & $1(\% 5)$ \\
CZ & $4(\% 19)$ & $12(\% 57)$ & $5(\% 21)$ \\
SAM & $3(\% 14)$ & $17(\% 80)$ & $1(\% 5)$ \\
AM & $1(\% 5)$ & $10(\% 21)$ & $10(\% 48)$ \\
\hline
\end{tabular}


Meropenem $=M E M$, Piperacillin $/$ tazobactam $=T Z P$, Ampicillin/Sulbactam $=S A M$, Amikacin $=A K$, Ceftazidime $=C A Z$, Tobramycin= TOB, Amoxycillin /clavulanic acid $=A M C$, Gentamycin $=C N$, Aztreonam =ATM., Cefepime $=$ FEP PM, Cefotaxime $=C T X$, Cefuroxime $=C X M, C e f t r i a x o n e=C R O$ ,Sulphamethazol/Trimetroprim $=S X T$,Ciprofloxacin $=C I P$, Cefoperazone $=C F P$, Cephazolin $=C Z$, Norfoflaxain $=$ NOR, Ampicillin $=A M, C$ efixime $=C F M$

When it comes to norfloxacin, sensitivity rate, it was \%86. Many researchers tested sensitivity of norfloxacin to E.coli (Karki et al., 2001, Ay et al., 2003).

Sensitivity rate of ciprofloxacin was showed in $86 \%$. Many researchers have tested the sensitivity of ciprofloxacin to E.coli (Turnidge et al., 2002, Aiyegoro et al., 2007, Mansouri et al., 2002). Our results were similar to Mansouri et al.,(2002) who also reported that percentage of ciprofloxacin sensitivity was $84.62 \%$ in Iran. It can be suggested that ciprofloxacin can be used for infections based on E.coli.

As for the sensitivity rate of cefotaxime, it was $80 \%$. Many researchers have tested resistance of cefotaxime to E.coli (Jones et al., 2004, Gönüllü et al., 2008. Our results were similar to Gonullu et al (2008) who also reported that sensitivity rate of cefotaxime was $84 \%$.

Sensitivity rate of aztreonam was showed in $76 \%$. Many researchers have tested the resistance of aztreonam to E.coli (Cho et al., 2011, Gonlugur et al., 2004, Igbal et al., 2002) Our results were similar to Iqbal et al (2002) who also reported that aztreonam sensitivity rate was $74 \%$.

When it comes to ceftazidime sensitivity rate, it was $71 \%$. Some researchers have reported that ceftazidime sensitivity rate from $99.6 \%$ to $4.5 \%$ (Rhonberg and Jones, 2007, Ozsahin et al., 2005). Our results were in compliance with previous researchers

As for the sensitivity rate of cefepime, it was $71 \%$. Some researchers have reported sensitivity rate cefepime to E.coli in clinical samples (Iqbal et al 2002, Ashgar, 2006, Albayrak and Kaya, 2009, Kumarasinghe, 2001). Our results were similar to Iqbal et al (2002) who also reported that cefepime sensitivity rate was $80 \%$.

As for sensitivity rate of cefixime was $62 \%$. Cefixime has a broad antibacterial spectrum and it is active against a wide variety at gram-negative organisms, including E.coli. Our results were similar to Iqbal et al. (2002) who also reported that cefixime sensitivity rate was $61 \%$.

As for sensitivity rate of ceftriaxone, it was 57\%. Many researchers have tested the resistance of ceftriaxone to E.coli. According to previous studies resistance of E.coli was from 0\%to 100\% (Koken et al., 2008, Matute et al., 2004, Ateş, 2007, Yuluğkıral, 2007, Kalantar et al., 2008, Uzun et al., 2006).

As for the sensitivity rate of piperacillin/ tazobactam, it was 57\%. Tazobactam seems to be the most promising betalactamase inhibitor, which has unlike clavulanic acid and sulbactam, its own antibiotic activity (Blahova et al., 1995).

Sensitivity rate of sulfamethoxazole/trimethoprim was showed in $52 \%$. Some researchers have reported sulfamethoxazole/trimethoprim sensitivity rate to E.coli in clinical samples (Gonlugur et al., 2004, Ery1lmaz et al., 2010, Rawat et al., 2010) Our results were similar to Gonlugur et al.(2004) ${ }^{33}$ who also reported that sulfamethoxazole /trimethoprim sensitivity rate was $55 \%$.

As for the sensitivity rate of cefoperazone, it was $48 \%$. Some researchers have reported sensitivity rate cefoperazone to E.coli in clinical samples (Ozsahin et al., 2005, Dean et al., 2008)

Sensitivity rate of cefuroxime was showed in $42 \%$. Some researchers have reported sensitivity rate cefuroxime to E.coli in clinical samples (İnan and Gurler 2004, Duman et al., 2010). In our study resistance of cefuroxime was detected $19 \%$. Our results were similar to Inan and Gurler (2004) who also reported that resistance of cefuroxime showed $14 \%$ in E.coli strains isolated from children with urinary tract infections.

As fort the sensitivity rate of amoxicillin-clavunat, it was \%38. Some researchers have reported amoxicillin-clavunat sensitivity rate to E.coli ( Uzun et al., 2006, Kader and Kumar, 2004).

As for the sensitivity rate of amikacin, it was 33\%. Some researchers have reported amikacin sensitivity rate to E.coli (Karki et al., 2001, Ekim et al., 1998, Çetin et al., 2006, Giray et al., 2012). In our study resistance of amikacin was detected $0 \%$. Our results were similar to Giray et al., (2012) who also reported that resistance of amikacin showed 0 $\%$ in E.coli strains obtained from urology outpatient clinic of Ege Medical Faculty in Izmir.

Among the aminoglycosides group, gentamycin sensitivity rate was $29 \%$. Some researchers have reported gentamycin sensitivity rate to E.coli from 1.5\% to 54\% (Koksaldi-Motor et al., 2010, Kutlu, 2007, Pieboji et al., 2004, Kalem et al., 2008). Our results were compliance with previous researchers. Koksaldi-Motor et al., (2010) reported that when it compared to previous year's data susceptibility of E.coli isolated from urine to gentamycin were decreased and also different resistance rate occurred different locations. 
As for the sensitivity rate of tobramycin, it was $19 \%$. Some researchers have reported tobramycin sensitivity rate to E.coli (Gonlugur et al., 2004, Sucu et al., 2004). Our results were similar to Gonlugur et al. (2004) who also reported that tobramycin sensitivity rate was $16.6 \%$.

As for the sensitivity rate of cefazolin, it was 19\%. Some researchers have reported that cefazolin sensitivity (Vlieghe, 2009, Arikan et al., 1995, Frederick, 2011). Our results were in compliance with previous researchers.

As for sensitivity rate of ampicillin/sulbactam was 14\%. Many researchers have tested sensitivity ampicillin/sulbactam to E.coli ( Toroglu et al., 2013, Khan and Zaman, 2006).

As for sensitivity rate of ampicillin was 5\%. Many researchers have tested the resistance of ampicillin to E.coli (Leblebicioğlu et al., 1994, Rawat et al., 2010, Ahmed et al., 2000). Our results were similar to Rawat et al. (2004) who also reported that aztreonam sensitivity rate was 5.71\% from Kumaun region.

In the present study, the lowest MAR index was 0 obtained from urine samples from female and male. In contrast to the highest MAR index was 0.65 obtained from a female. Out of 21 isolates, 3 (14\%) isolates showed Multiple Antibiotic Resistance ten to thirteen antibiotics. The MAR index were determined 0.25 and above (Table 2). Some researchers have reported Multi-Drug Resistance rate to E.coli from 2\% to 97\% ( Al- Mardeni et al., 2009, Mathai et al., 2008, Al-Tawfiq, 2006). Our results were in compliance with previous researchers. Study shows that multiple resistance is a common hospital pathogen.

Table 2: Multiple antibiotic resistance (MAR) index among 21 Escherichia coli urine samples

\begin{tabular}{|l|c|c|}
\hline Source of isolates & Total isolates & MAR index \\
\hline Male & 1 & 0,5 \\
\hline Male & 2 & 0.15 \\
\hline Male & 1 & 0.45 \\
\hline Female & 2 & 0.05 \\
\hline Female & 1 & 0.65 \\
\hline Female & 1 & 0.05 \\
\hline Female & 3 & 0.1 \\
\hline Female & 9 & 0 \\
\hline Male & 1 & 0 \\
\hline Total & 21 & \\
\hline
\end{tabular}

In conclusion, it is suggested that meropenem, norfloxacin and ciprofloxacin, cefotaxime, aztreonam could be better for the treatment of infections based on E.coli according to the present study. Ampicillin/sulbactam and ampicillin were not-advisible antibiotics for E.coli infections according to results of the present study.

\section{REFERENCES}

Ashgar, AH. 2006. Frequency and antimicrobial susceptibility patterns of bacterial pathogens isolated from septisemic patients in Makkah hospitals. Saudi Med J, 27(3):361-367.

Ahmed AA, Osman H., Mansour AM, Musa HA, Ahmed AB,Karrar Z and Hassan HS.. Antimicrobial agent resistance in bacterial isolates from patients with diarrhea and urinary tract infection in Sudan. The American Soc Trop Med Hygiene, 63(5, 6), , pp. $259-263,2000$.

Aiyegoro, O.A., O.O. Igbinosa, I.N. Ogunmwonyi, E.E. Odjadre, O.E.Igbinosa and A.I. Okoh, 2007. Incidence of urinary tract infections(UTI) among children and adolescents in lle-Ife, Nigeria. African J.Microbiol. Res., 013-019

Albayrak, N. and S. Kaya,. Extended spectrum beta lactamases production and antimicrobial resistance ratio of the Esherichia coli and Klebsiella pneumoniae strains isolated from various clinical specimens. Türk Microbiol Cem. Derg., 39: 16-21,2009.

Al-Mardeni RI, Batarseh A, Omaish L, Shraideh M, Batarseh B, Unis N. Empirical treatment for pediatric urinary tract infection and resistance patterns of uropathogens, in Queen Alias Hospital and Prince A'lsha Military Center. Jordan. Saudi J Kidney Dis Transplant; 20: 135-9, 2009.

Al-Tawfiq JA. Increasing Antibiotic Resistance Among Isolates of Escherichia coli Recovered From Inpatients and Outpatients in a Saudi Arabian Hospital. Infect Control Hosp Epidemiol; 27:748-753,2006.

Arıkan S, Gür D, Hayran M,ve ark Hastane dışı enfeksiyonlara yol açan gram negatif bakterilere karşı cefamet'in in vitro etkinliği. Mikrobiol Bült 1995; 29:14-19.

Ateş F. The analyse of urine culture results in patients with lower urinary tract infection, Türk Üroloji Derg;33(2):223-7,2007

Ay S, İşeri LA, Duman B. Antibiotic Susceptibilities of Gram Negative Microorganisms Isolated from Urine Samples. İnönü ÜnivTip Fak Derg.,10(2) 59-62, 2003

Barišić Z, Babić-Erceg A, Borzić E, Zoranić V, Klaiterna V, Carev M. Urinary tract infections in South Croatia: aetiology and antimicrobial resistance. Int J Antimicrob Agents, 22, 61-64,2003.

Bauer, A.W, Kirby, WM.M, Sherris, JC., Turck, M. Antibiotic susceptibility testing by a standart.. CLSI., Performance standards for antimicrobial susceptibility testing; 15th informational supplement. 1966. 
Blahova J, Hupkova M, Kremery V Sr. The effectivesness of so called potentiated penicillins (augmentin and tazobactam) in vitro. Cas Lek cesk 1995: 134: 558-61

Blomgran, R., Zheng L, Stendhal O. 2004. Uropathogenic Esherichia coli trigger oxygen-dependent apoptosis in human neutrophils through the cooperative effect of type 1 fimbriae and lippolysaccharide. Infect. Immun., 72:4570-4578.

Cetin ES, Demirci M, Kaya S, Arıdogan BC, Adiloglu AK, Goksu Y, Gonulates N. Antibiotic susceptibilities of Escherichia coli, Klebsiella pneumoniae and Enterobacter strains isolated from blood specimens. Turk Mikrobiyol Cem Derg 36 (1) : 20 - 24, 2006

Cho SH, Lim YS, Park MS, Kim SH a, Yeon-Ho Kang YH. 2011. Prevalence of Antibiotic Resistance in Escherichia coli Fecal Isolates From Healthy Persons and Patients With Diarrhea. Public Health Res Perspect 2(1), 41-45.

CLSI., 2005. Performance standards for antimicrobial susceptibility testing; 15th informational supplement. CLSI / NCCLS M 100S 15. Clinical and Laboratory Standards Institute, Wayne, PA().

Conway P and G. Macfarlane,1995.Microbial ecology of the Human large intestine. In:human Colonic Bacteria: Role in nutrition , Physiology and pathology, GibsonG and G. Macfarlane( Eds.) CRC Press, London

Cowan SF, Steel KJ (1970). Manual for the Identification of the Medical Bacteria Cambridge: Cambridge University Press. pp. 7-122

Dean DC., Krahe D., Wareham D.2008. Antimicrobial resistance in community and nosocomial Esherichia coli urinary tract isolates , London 2005-2006. Annals of Clinical Microbiology and Antimicrobials 7:13,1-4.

Duman Y., Güçlüer N., Serindag A., Tekerekoglu MS. Antimicrobial suspectibility of E.coli strains and presence of extendedspectrum beta lactamase. Firat Tip Derg., 15(4) 197-200, 2010.

Ekim M., Kuluglu Z., Aysev D., Can S. 1998. Changes in antibiotic sensitivity in urinary tract infection caused by Esherichia coli Journal of the Turkish Nephrology, 3 141-144.

Eryilmaz M., Eylül -Bozkurt M., Yildiz MM., Akin A. Antimicrobial resistance of urinary Esherichia coli isolates. Trop J of Pharm Res, 9(2) 205-209, 2010.

Feng P and S.D. Weagant.,2009. Bacteriological analytical manual 8th. Edn.,Chapter 4 http:ww w fd .gov/Food/science Research / laboratoryMethods / Bacteriological Analytical Manula Bam /UCM 064948.

Frederick A.,2011. Esherichai coli, it prevalence and antibiotic resistant in Malasia: A mini review . Microbiology Journal 1(2) 47-53.

Giray B., Ucar FB., Aydemir SS.2012. Characterization of uropathogenic Esherichia coli strains obtained from urology outpatient clinic of Ege Medical Faculty in Izmir. Turk J Med Sci. 42(1) 1328-1337.

Gonlugur, U., M.Z. Bakici, I. Akkurt and T. Efeoglu, 2004. Antibitic susceptibility patterns among respiratory isolates of Gram negative bacilli in a Turkey university hospital. BMC Microbiol., 4: 1-5

Gönüllü N., Canberk MB., Filiz O., Altinkum S., Kucükbasmacı O., Aygun G., Altas K.. Antimicrobial susceptibilities and beta lactam resistance phenotypes of Esherichia coli strains isolated from various clinical samples.Ankem Derg 22(2) 64-68, 2008.

Iqbal M, Patel IK, Shah SH, Ain Q, Barney N, Kiani Q, Rabbani KZ, Zaidi G, Mehdi B. Susceptibility patterns of Escherichia coli: prevalence of multidrug-resistant isolates and extended spectrum beta-lactamase phenotype J Pak Med Assoc. 2002 Sep;52(9):407-11.

Inan N U, Gurler N. Investigation of Antibiotic Resistance and Some Virulence Factors of Escherichia coli Strains Isolated from Children with Urinary Tract Infections. Ankem Derg; 18(2):89-96, 2004.

Jha, N and Bapat SK. 2005. A study of sensitivity and resistance of pathogenic microorganisms causing UTI in Kathmandau valley. Kathmandu Univ. Med J., 3:123-129.

Jones ME, DC, Draghi., C, Thornsberry., JA, Karlowsky., DF, Sahm., RP, Wenzel. 2004. Emerging resistance among bacterial pathogens in the intensive care unit a European and North American Surveillance study. Ann Clin Microbiol, 3(14) 1-11.

Kader, A.A. and A. Kumar,. Prevalence and antimicrobial susceptibility of extended-spectrum $\beta$-lactamase-producing Escherichia coli and Klebsiella pneumoniae in a general hospital in Saudi Arabia. Saudi Med J., 25: 570-574,2004.

Kalantar E, Motlagh ME, Lornejad H, Reshadmanesh N. Prevalence of urinary tract pathogens and antimicrobial susceptibility patterns in children at hospitals in Iran. Iranian Journal of Clinical Infectious Diseases, 2008;3(3):149-153.

Kalem F., Gunden NS., Arslan U., Tuncer I. Antimicrobial susceptibility of Escherichia coli strains isolated in urin samples. ANKEM Derg 22: 193-197,2008.

Karki T., Truuaslu K., Vainumae., Mikellsaaar M. Antibiotic Susceptibility Patterns of Community- and Hospital-acquired Staphylococcus aureus and Escherichia coli in Estonia. Scand J Infect Dis 33: 333-338, 2001.

Khan AU and Zaman MS. Multiple drug resistance pattern in Urinary Tract Infection patients in Aligarh. Biomedical Research 2006; 17 (3): 179-181.

Koken G, Asık G, Ciftci H, Cetinkaya Z, Aktepe O.C, Yılmazer M. Efficiency of Fosfomycin Trometamol on Escherichia coli Strains from Community Acquired Urinary Tract Infections. Ankem Derg, 22(1):23-27,2008.

Koksaldi-Motor V., Tutanç M., Arıca V., Arıca S., Ay B. Suspectibility of Uropathogen Esherichia coli strains to commonly used antibacterail agents in urinary tract infections. Ankem Derg, 2010,24(4) 198-201, 2010.

Krumperman, PH. 1985. Multiple antibiotic resistance indexing of Escherichia coli to identify high-risk sources of fecal contamination of foods. App. Environ. Microbiol., 46:165-170.

Kumarasinghe G, Chow C, Tambyah PA. Widespread resistance to new antimicrobials in a university hospital before clinical use. Int J Antimicrob Agents ., Oct;18(4):391-393. 2001.

Kutlu S, Kutlu M. Antibiotic susceptibility of Escherichia coli strains isolated in urinary tract infections in Didim, Turkey. Turk J Infect; 21(2): 81-83, 2007.

Leblebicioglu H., Gunaydın H., Sanic A.,Buyukalpelli R.1994. Comparative İn-vitro susceptibility of betalactam and betalactam/betalactamase inhibitor antibiotics against gram negative rods isolated from urine cultures. Mikrobiyol Bült., 28 218-222.

Lim KT., Yasin R.,Yeo CC.,Puthucheary S., Thong K.L. Characterization of multidrugresistant ESBL producing esherichia coli isolates from hospitals in Malasia. J. Biomed Biotechnol ., 1-10, 2009 
Mansouri S, Shareif S, Ahmad K (2002). Antimicrobial resistance pattern of E. coli causing urinary tract infections and that of human faecal flora in southeast of Iran. Iran Med. Journal 8: 123-128.

Mathai E, Chandy S, Thomas K, Antoniswamy B, Joseph I, Mathai M, Sorensen TL, Holloway K.. Antimicrobial resistance surveillance among commensal Escherichia coli in rural and urban areas in Southern India. Trop Med Int Health. Jan;13(1):41$5,2008$.

Matute AJ, Hak E, Schurink CA, McArthur A, Alonso E, Paniagua M, Van Asbeck E, Roskott AM, Froeling F, Rozenberg-Arska M, Hoepelman IM. Resistance of uropathogens in symptomatic urinary tract infections in León, Nicaragua. Int J Antimicrob Agents.,23(5):506-9,2004.

Matyar, F., Kaya, A and Dinçer, S. 2008. Antibacterial agents and heavy metal resistance in Gram-negative bacteria isolated from seawater, shrimp and sediment in Iskenderun Bay, Turkey. Sci. Total Environ., 407:279-285.

Nataro J.P and J.B Kaper,1998. Diarrheagenic Esherichia coli .In: Foodborne Disease Handbook, Hui,Y.H., JR. Gorham, K.D.Murrell and D.O Cliver ( Eds). Marcel Decker, Inc., New York, pp:169-213.

Okeke IN, Lamikanra A, Edelman R. 1999. Socioeconomic and behavorial factors leading to acquired bacterial resistance to antibiotics in developing countries. Emerg.Infect. Dis. 5:18-27.

Olowe OA, Olayemi AB, Eniola KIT and Adeyeba AO.2003.Aetiological agents of diarrhoea in children under 5 years of age in Osogbo. Afr.J. Clin and Exp. Microbiol 4(3):62-66.

Ozsahin D., Digrak M., Kiran OE.2005. The Investigation on resistance Properties of Esherichia coli against Beta Lactam Groups Antibiotics. KSU, Journal Of science and Engineering 8(2)8-12.

Piéboji JG, Koulla-Shiro S, Ngassam P, Adiogo D, Njine T, Ndumbe P.Antimicrobial resistance of Gram-negative bacilli isolates from inpatients and outpatients at Yaounde Central Hospital, Cameroon. Int J Infect Dis, 8(3):147-54, 2004.

Prakash S. Dayalan JA and Edison N 2011. Prevalence of Bacteriuria In Jeyaseharan Hospital of South India and their antibiogram. Asian Pacific Journal of Tropical Biomedicine, 105-108.Cambridge University Press. pp. 7-122 .

Rawat DV, Umesh D, Paul MP. 2010. Antibiotic Resistance Pattern of Urinary Tract Isolates of Escherichia coli from Kumaun Region. National Journal of Integrated Research in Medicine 1(4): 43-46.

Rhonberg PR and Jones RN.2007. Contemporary activity of meropenem and comparator broad-spectrum agents: MYSTIC program report from the United States component (2005). Diagn Microbiol Infect Dis. 2007 Feb;57(2):207-15

Sucu N, Boz GA, Bayraktar O, Caylan R, Aydın K, Koksal İ. Th e change of antibiotic susceptibilities of uropathogen Escherichia coli strains in years. Klimik Dergisi 2004; 17: 128-131.

Swartz MN,1994.Hospital-acquired diseases with increasingly limited therapies. Proc Natl Acad Sci USA, 91:2420-2427.

Tobih JE, Taiwo SS, Olowe OA, Olaosun OA, Adejumo SO.2006. Microbiological profiles of discharging ears in Osogbo, Nigeria. Trop. Doc. 36(3):165-166.

Toroglu S and Keskin D. Antimicrobial Resistance and Sensitivity among Isolates of Klebsiella pneumoniae from Hospital Patients in Turkey. Int J Agri Biol, 13(6) 941-946,2011

Toroglu, H. Avan, D. Keskin. Beta- Lactamases production and Antimicrobial resistance ratio of Pseudomonas aeruginosa from hospitalized patients in Kahramanmaraş, Turkey, Journal of Environmental Biology, 34 (4), 695-700, 2013.

Turnidge J., Bell J., Biedenbach J and Jones R.N, 2002Pathogen occurrence and antimicrobial resistance trends among urinary tract infection isolates in the Asia-Western Pacific Region: report from the SENTRY Antimicrobial Surveillance Program, 19981999. International Journal of Antimicrobial Agents 2002, 20, 10-17.

Uzun K., Teke T., Yavuz Z. ., G..Surveillance of antimicrobial resistance and susceptibility in bacterai isolated from pulmonart critical care. Tip Araşt Derg., 4(3) 8-13, 2006.

Vlieghe E., Phoba MF., Muyembe Tamfun JJ., Jacobs J.. Antibiotic resistance among bacterial pathogens in Central africa: a review of the published literatue between 1995 and 2008. Int J Antimicrob Agents, 34, 295-303, 2009.

Yakupoguları, Y., A, Gunduz., M, Ozcan., M, Dogukan., A, Seyrek., M, Yılmaz. 2006. Susceptibility of Staphylococcus aureus Strains to Ciprofloxacin, Ofloxacin, Levofloxacin and Moxifloxacin. Firat Tip Derg; 11(1): 45-47.

Yılmaz N., Köse Ş., Ağuş N., Ece G., Akkoçlu G., Kıraklı C. Microorganisms Isolated from Blood Cultures of Intensive Care Unit Patients, their Antimicrobial Susceptibility and Etiological Agents in Nosocomial Bacteremia. Ankem Derg 24(1):12-19,2010.

Yuluğkural Z, Mutlu B. Susceptibility of Escherichia colistrains isolated from urine cultures to some commonly used antibacterial agents Medical Journal of Trakya University; 24: 6-11, 2007

\section{Authors Contributions}

All the authors have contributed significantly in study design, experimentation, data analysis and manuscript drafting.

$$
--0 \text {-- }
$$

